\title{
The future of chlamydia screening
}

In November 1996 the chief medical officer's (CMO) expert advisory group on Chlamydia trachomatis was set up to advise on the issues associated with screening programmes for chlamydia. ${ }^{1}$ Arising from their recommendations the Department of Health set up a pilot study of opportunistic chlamydia screening, ${ }^{2}$ based in primary care settings, in Portsmouth and the Wirral. Recruitment of patients began in September 1999 for 1 year. The aim of the study is to evaluate the acceptability, feasibility, and costs of providing such a service. Among the main objectives of the pilot study are those of establishing the proportion of women offered and accepting the test, evaluating public and professional educational methods and materials, assisting the development of a model for a national chlamydia screening programme along with the costs and implications for NHS staffing and, in the long term, preventing the possible complications of infection.

Women aged over 16 and below 25 who have ever been sexually active are offered opportunistic screening by a nucleic acid amplification technique, on a urine specimen, when they attend their general practitioner, family planning, termination of pregnancy, genitourinary medicine (GUM), colposcopy, gynaecology, or antenatal clinic. Women under the age of 16 are included if they present for a sexual health reason and are considered to be Gillick competent (able to make informed decisions). Men between 16 and 24 attending genitourinary medicine, Brook clinics in the Wirral, and Sex Sense (dropin centres for young people) in Portsmouth are also offered urine testing. Participants are eligible for repeat screening if they change their sexual partner.

Patients can choose how they wish to be contacted with their results whether negative or positive. Those found to be positive on screening are asked to contact the local research nurses to arrange further management. This includes treatment, partner notification, and the recommendation to attend a GUM clinic for a full sexual health screen. In Portsmouth the research nurses are situated within the GUM department and can offer immediate clinic appointments for patients and their partners throughout working hours.

The setting up of the pilot study has identified several general issues. The first of these is what population to screen. Women aged over 25 have been excluded because the prevalence rates of infection are less. In Portsmouth 30000 women, out of a total population of approximately 550000 , fall within the 16-24 age range and to offer screening to just this group has stretched local resources. Men are not routinely included because they are less likely than women to attend healthcare settings where screening would be feasible and the sequelae of infection are less serious.

For large scale screening programmes urine samples rather than swabs requiring an invasive examination are likely to be more acceptable. In the pilot study these specimens are being tested using DNA amplification techniques with their known superior sensitivity over other methods in current widespread use. ${ }^{3}$ However, these tests are more expensive and were only available to $6 \%$ of GUM clinics in the United Kingdom in a 1999 survey. ${ }^{4}$

Acceptability of screening to both patients and healthcare professionals is essential if a screening programme is to be successful. Certainly in Portsmouth the large number of women who accepted testing from day one of the study suggests that reluctance to be tested for a sexually transmitted infection is not a problem. Whether or not general practitioners will be keen to participate is another matter. In Portsmouth many general practitioners were enthusiastic about joining the pilot study. Others had initial anxieties, quoting reasons such as the difficulty and time pressures of discussing sexual issues with patients attending for a non-related matter.

The CMO's report recognised that both public and professional education would be needed before starting a screening programme. In Portsmouth relevant healthcare workers were visited, usually on more than one occasion, by the research nurses to explain the background to the pilot study and the practicalities of its implementation. In addition, larger educational meetings were held requiring GUM input. A planned district-wide advertising and education programme one month into the study was shelved in Portsmouth because public interest in screening led to laboratory testing facilities being temporarily overwhelmed.

Issues specific to GUM have also become apparent. Although positive patients can arrange to collect treatment elsewhere 9 months into the study, the evidence from Portsmouth is that the substantial majority of them are willing to access GUM services. Furthermore, over $70 \%$ of their traceable contacts have attended as well. This high level of acceptance has considerable resource implications for GUM clinics which will require extra staff and facilities to see these people. It is probable that by the end of the screening period the number of positive women identified on the Portsmouth arm of the pilot study and seen in GUM clinics will approach 2000. A similar number of partners are expected to be seen. It is important that patients coming to GUM clinics understand that the results of further tests remain fully confidential.

Treatment for positive patients in the study is with doxycycline, erythromycin, or azithromycin. For younger patients who might find difficulty explaining away a course of antibiotics or for those whose compliance may be uncertain ${ }^{56}$ azithromycin is proving to be especially useful and the single dose therapy ${ }^{7}$ can be directly observed. There is, however, a financial cost. ${ }^{8}$

The overall positivity rate in the pilot study so far is approximately $10 \%$ at each site. At these levels it is extremely likely that the pilot study will inform a national screening programme to be set up in the near future. Whether this will follow the same methodology is not yet known. Other models not involving primary care are feasible with women offered direct access to laboratories for testing of self collected urine specimens or vulval swabs. ${ }^{9} 10$ The pilot study will leave some questions unanswered, such as the optimum interval between screening episodes and long term health gain.

Whatever the future screening model some central agency, probably in every health district, will be needed to manage positive patients, arrange full sexual health screening, and initiate partner notification. ${ }^{11}{ }^{12}$ Existing GUM departments already have the necessary expertise to provide these services.

GUM clinicians should enthusiastically welcome a national screening programme for chlamydia. Preparations should start now to ensure that resources will be available to enable them to provide a service for the large number of positive patients who will be identified.

J M TOBIN

V HARINDRA

L J TUCKER

Department GU Medicine, St Mary's Hospital, Portsmouth, Hants, $\mathrm{PO} 36 \mathrm{AD}$ 
1 CMO's Expert Advisory Group. Chlamydia trachomatis: summary and conclusions of CMO's Expert Advisory Group. sions of 1998.

2 Chlamydia trachomatis screening pilot project initiation document. London: Department of Health, March 2000.

3 Taylor-Robinson D, Renton A. Diagnostic tests that are worthwhile for patients with sexually transmitted bacterial infections in industrialized countries. Int $\mathcal{F}$ STD AIDS 1999;10:1-4.

4 David LM. Diagnostic tests and specimens used to screen for Chlamydia trachomatis in genitourinary medicine clinics in the United Kingdom. Int $\mathcal{F}$ STD AIDS 1999;10:527-30

5 Carlin EM, Barton SE. Azithromycin as the first-line treatment of non-gonococcal urethritis (NGU): a study of follow-up rates, contact attendance and patients' treatment preference. Int 7 STD AIDS 1996;7:185-9.

6 Hammerschlag MR, Golden NH, Oh MK, et al. Single dose of azithromycin for the treatment of genital chlamydial infections in adolescents. $\mathcal{F}$ Pediatr 1993;122:961-5.
7 Martin DH, Mroczkowski TF, Dalu ZA, et al. A controlled trial of a single dose of azithromycin for the treatment of chlamydial urethritis and cervicitis. The Azithromycin for Chlamydial Infections Study Group. N Engl f Med 1992;327:921-5.

8 Magrid D, Douglas JM Jr, Schwartz JS. Doxycycline compared with azithromycin for treating women with genital Chlamydial trachomatis infections: an incremental cost-effectiveness analysis. Ann Intern Med 1996;124:389-99.

9 Stephenson J, Carder C, Copas A, et al. Home screening for chlamydial genital infection: is it acceptable to young men and women? Sex Transm Inf 2000;76:25-7.

10 Carder C, Robinson AJ, Broughton C, et al. Evaluation of self-taken samples for the presence of genital Chlamydia trachomatis infection in women using the ligase chain reaction assay. Int $\mathcal{F}$ STD AIDS 1999;10:776-9.

11 White C, Wardropper. Chlamydia in a district general hospital: an audit of treatment and contact tracing. Int F STD AIDS 1999;10 57-9.

12 Rani Jarvis R, Curless E, Considine K. Outcome of contact tracing for Chlamydia trachomatis in a district general hospital. Int $\mathcal{f}$ STD AIDS 1999;10:250-3.

\section{Research methodology in sexual health}

A new series edited by Judith Stephenson and Abdel Babiker (see p 244) begins in this issue. It came about because of the observation that researchers in sexually transmitted infections and related subjects often face specific problems that are either unique to the specialty, or have a unique flavour-no pun. The series will try to address specific knots in STI research, using examples from the field. Future topics include: measurement of sexual behaviour; study size; cohort studies; case-control studies, survey methods; questionnaire design; mathematical modelling; selection of controls; and uses and abuses of geomapping software.

We would welcome any other suggestions. 